\title{
Dimensões Organizacionais e Pessoais de Promoção de Bem-Estar e Felicidade no Trabalho
}

\author{
Organizational and Personal Dimensions to Foster Welfare and Happiness at Work
}

Danilo Ciconi de Oliveira

Centro Universitário da Fundação de Ensino Octávio Bastos. SP, Brasil.

E-mail: danilociconipsi@gmail.com

\begin{abstract}
Resumo
Na sociedade contemporânea há uma espécie de centralidade do trabalho na vida das pessoas, servindo esse como principal organizador da rotina e das relações e, inclusive, sendo elemento que compõe parte da identidade dos indivíduos. Assim, em muito está atrelado o trabalho às vivências emocionais mais importantes. Nesse sentido, esforços devem ser tomados pelos indivíduos e pelas Organizações para tornar o contexto laboral promotor de qualidade de vida, de bem-estar e de felicidade. O objetivo deste artigo é apresentar um panorama da produção científica acerca dos fatores ambientais e pessoais associados à promoção de bem-estar e felicidade no contexto laboral. Trata-se de um estudo qualitativo de caráter exploratório. Foi realizada busca bibliográfica em bases indexadas e recuperados artigos publicados em periódicos nos últimos dez anos. Os resultados apresentam algumas especificidades dos constructos relacionados à área (qualidade de vida, bem-estar, felicidade), algumas possibilidades de ações organizacionais de promoção de bem-estar e felicidade e, principalmente, descrevem estudos que encontraram relações positivas entre diversas variáveis, dos indivíduos e das Organizações, e a produção de felicidade no contexto do trabalho. A conclusão destaca a necessidade dos modelos de Gestão de dar primazia ao fator humano nas Organizações, inclusive, por ocasião de compor o Planejamento Estratégico Organizacional.
\end{abstract}

Palavras-chave: Felicidade. Bem-estar no Trabalho. Gestão de Pessoas. Comportamento Organizacional. Psicologia do Trabalho.

\begin{abstract}
In contemporary society, there is a kind of centrality of work in people's lives, serving as the main organizer of our routine and our relationships, and even being an element that makes up part of the individuals' identity. Thus, work is closely linked to our most important emotional experiences. Thus, efforts must be taken, by individuals and organizations, to make the work context a motivator of quality of life, well-being and happiness. The purpose of this article is to present an overview of scientific production about the environmental and personal factors associated with the promotion of well-being and happiness in the workplace. It is an exploratory qualitative study. A bibliographic search was performed on indexed databases and articles published in journals in the last ten years were retrieved. The results show some specificities of the constructs related to the area (quality of life, well-being, happiness), some possibilities of organizational actions to promote well-being and happiness and, mainly, describe studies that found positive relationships between several variables, of the individuals and organizations, and the production of happiness in the work context. The conclusion highlights the need for Management models to give priority to the human factor in Organizations, including when composing the organizational Strategic Planning.
\end{abstract}

Keywords: Happiness. Well-Being at Work. People Management. Organizational Behavior. Work Psychology.

\section{Introdução}

$\mathrm{Na}$ atualidade, entende-se que o trabalho exerce importantes funções psicossociais no desenvolvimento adulto (para muito além da mera subsistência); entre essas, a definição da própria identidade do indivíduo e de seu papel na sociedade (visto que, em torno desse se organizam agendas e rotinas e se apresentam inúmeras oportunidades de interação pessoal) (PASCHOAL; TORRES; PORTO, 2010). Na sociedade de mercado, a identidade ocupacional e a pessoal se sobrepõem em largos espaços e é o trabalho o grande organizador da vida humana (SILVA; TOLFO, 2012). Há uma espécie de centralidade do trabalho na vida das pessoas, todavia, esta compreensão é, historicamente, construída e remete a um discurso atrelado à consolidação do Capitalismo como modelo econômico, prioritariamente, vigente em um Mundo globalizado. A despeito da forja artificial desta ideia de centralidade do trabalho na vida humana, estando essa presente, é essencial que se façam esforços no sentido de construção de instituições de trabalho que sejam promotoras potenciais de saúde e de felicidade (FARSEN et al, 2018).

Ora, se o ser humano passa a maior parte do seu tempo no trabalho é, então, um grande desafio organizacional tornar as pessoas mais felizes (PEDROSO, 2010) e, por conseguinte, mais motivadas e comprometidas (ALVES, 2011). Paschoal, Torres e Porto (2010) destacam, não obstante, que poucos são os modelos empíricos e teóricos que se preocupam em determinar as variáveis que se relacionam (ou que determinam) a felicidade no contexto do Mundo do Trabalho. 
Os elementos indispensáveis para a construção de Organizações saudáveis parecem girar em torno da qualidade de vida, do bem-estar e da felicidade no trabalho (FARSEN et $a l, 2018$ ), sendo estes elementos que devem ser encarados não apenas pelo seu valor instrumental, ou seja, porque podem contribuir com o desempenho profissional, mas, sobretudo, pelo fato de serem intrinsicamente valiosos (REGO, 2019).

Ademais, o campo da felicidade no trabalho é de grande relevância para a área da Saúde Pública (MAIA; MAIA, 2019). Assim, é de exímio valor caracterizar melhor os determinantes do bem-estar e da felicidade humana no trabalho. Visto que ocupa posição central na vida humana, podendo ser fonte de realização e de felicidade, o trabalho precisa ser analisado a partir, também, de suas dimensões físicas e psicossociais (SILVA; TOLFO, 2011).

Diante do exposto se tem como objetivo para este texto apresentar um panorama, a partir da produção científica específica, sobre fatores ambientais (das Organizações) e pessoais (fatores intrínsecos e próprios da personalidade) associados à produção de bem-estar e felicidade no contexto laboral.

\section{Desenvolvimento}

\subsection{Metodologia}

Trata-se de um estudo qualitativo de caráter exploratório. Foi realizada busca bibliográfica nas bases de dados indexadas e, a partir dessa feita uma revisão da literatura científica relacionada ao tema, apontando as principais contribuições à área. Recuperam-se os artigos de revistas científicas publicados nos últimos dez anos. Tendo por base o material recolhido se propôs tecer reflexões acerca das contingências, do Mundo do Trabalho, que influenciam a percepção de bemestar e a felicidade (sobretudo, no contexto laboral). Os dados recolhidos foram sintetizados e discutidos ao longo do escopo deste artigo.

\subsection{Bases conceituais e ações institucionais de promoção de bem-estar e felicidade no trabalho}

Inicialmente, é importante destacar que, conforme Farsen et al. (2018) enunciam, há diferenças importantes entre os constructos teóricos de qualidade de vida, bem-estar e felicidade no trabalho. Os autores analisaram a presença desses conceitos em publicações científicas brasileiras e internacionais e entenderam que, enquanto qualidade de vida no trabalho costuma estar relacionada à condição física de saúde; bem-estar e felicidade laboral dizem respeito às vivências emocionais e sentimentos dos indivíduos no trabalho. Maia e Maia (2019) delimitam, ainda mais, o constructo bem-estar no trabalho, definindo-o como o conjunto entre satisfação no trabalho, envolvimento com o trabalho e comprometimento organizacional afetivo. É sobre estas vivências subjetivas (bem-estar e felicidade) que se debruça este artigo.

Nos últimos anos, observa-se crescimento nos estudos sobre felicidade no contexto organizacional (ROCHA SOBRINHO; PORTO, 2012). Couto e Paschoal (2017) apregoam que as Organizações tendem, na contemporaneidade, a se atentar às necessidades de seus colaboradores e a realizar variadas ações voltadas à saúde do trabalhador: ginástica laboral, ambiente para relaxamento, automassagem, comemoração de aniversários, ambiente com musicalização etc. Nessa perspectiva, a Saúde Mental também é considerada alvo dessas intervenções, ainda que, não raramente, não tenha tanta relevância, no planejamento organizacional, quanto são as ações que buscam impactar a ergonomia do ambiente de trabalho.

Paschoal, Torres e Porto (2010) teceram correlações positivas entre a qualidade do suporte social e organizacional recebido no ambiente de trabalho e o bem-estar dos profissionais avaliados. Destaca-se que os autores entrevistaram mais de 400 participantes e que tomaram como dimensões de análise múltiplos fatores, como as emoções experimentadas no trabalho (humores positivos e negativos), a realização pessoal, modelos de gestão de desempenho empregados, carga laboral, salários e critérios de ascensão e promoção. O principal fator de realização e afeto positivo foi o modelo de gestão de desempenho empregado; por sua vez, $\mathrm{o}$ afeto negativo esteve mais intimamente relacionado com a carga de trabalho realizada pelos participantes.

Entende-se, a partir daí, os modelos de gestão humanizados e que preconizem respostas contingentes ao bom desempenho dos profissionais são mais passíveis de produzir vinculação ao trabalho e felicidade laboral. Por outro lado, a carga horária e de tarefas excessivas tende a ser um dos mais importantes promotores de mal-estar no ambiente organizacional. Pessoas que cumprem longas jornadas de trabalho, realizando tarefas cansativas, que não possuem folgas corriqueiramente ou que permanecem muito tempo sem sair de férias costumeiramente apresentam sintomas como cansaço, fadiga, mau humor, estresse e, até mesmo, depressão (COUTO; PASCHOAL, 2017).

Rego (2019) estabelece correlações entre bem-estar (felicidade) no trabalho e produtividade, a partir de um estudo com 272 profissionais de 132 instituições diferentes. O pesquisador avalia, a partir de técnicas de autorrelato, que os profissionais com melhores índices de bem-estar no trabalho se percebem como detentores de melhor desempenho individual. O autor sugere cautela ao observar tal resultado, por conta de se tratar de estratégia de pesquisa autorreportada. Não obstante, destaca que pode ser pertinente o entendimento de que a percepção de felicidade pode contribuir, em nível pessoal, com uma atitude individual de maior empenho, cooperação e foco em resultados, gerando, assim, realmente, maior produtividade.

Também tentaram encontrar relações lógicas (de causa e efeito) entre conceitos organizacionais recentes da Administração de Empresas - inovação, competitividade, 
desempenho ambiental, sustentabilidade, qualidade de vida, gestão do conhecimento etc. - e felicidade os pesquisadores De Carvalho, Gonçalves e Pardini (2010). Os autores equiparam os conceitos de felicidade e de bem-estar subjetivo - termo da Psicologia Positiva que é referente a um constructo que engloba aspectos emocionais (emoções experimentadas pelo indivíduo) e cognitivos (julgamento sobre a satisfação com relação à vida em geral). Foram utilizados, para análise, dados secundários, obtidos de diversas instituições de pesquisa. Foi identificado, a partir de análises estatísticas, que todas as variáveis estudadas apresentam, sem exceções, relações significativas e positivas com a felicidade (inclusive, constructos como competitividade e desempenho econômico). O constructo com menor intensidade foi a sustentabilidade, enquanto qualidade de vida apresentou a maior. Entende-se qualidade de vida, neste estudo, como fator antecedente à felicidade.

Os autores inferem, por fim, que a criação de um ambiente favorável à felicidade passa, então, por estratégias que potencializem o uso de tecnologias de informação e comunicação, a inovação e, por conseguinte, a competitividade (do país ou da Organização), visando desenvolvimento econômico, fator preponderante para a qualidade de vida (DE CARVALHO; GONÇALVES; PARDINI, 2010).

Alves (2011), por seu turno, enumera algumas ações de promoção de qualidade de vida que, costumeiramente, são adotadas pelas organizações e que tendem a produzir efeitos na motivação e na felicidade dos colaboradores: ginástica laboral e exercícios físicos, treinamento e desenvolvimento dos trabalhadores, ergonomia, programas de benefícios, avaliação de desempenho, de higiene e segurança do trabalho, estudo e descrição de cargos e salários, controle de álcool e drogas, preparação para a aposentadoria, orientações nutricionais, terapias alternativas, musicoterapia e antitabagismo. Maia e Maia (2019) apontam que bem-estar no trabalho pode ser alcançado a partir de ações organizacionais fáceis e baratas, em programas de intervenção ou de prevenção.

Nesta perspectiva, Couto e Paschoal (2017), supracitados, realizaram estudo com 130 participantes, que teve como objetivo avaliar o impacto de ações organizacionais voltadas à promoção da saúde do trabalhador (ginástica laboral, ambiente para relaxamento, automassagem, comemoração de aniversários, ambiente com musicalização etc.) sobre o bem-estar dos colaboradores. Os pesquisadores encontraram correlação entre a frequência de participação dos colaboradores em ações de promoção de saúde, realizadas pela Organização, e a redução de afetos negativos relacionados ao ambiente de trabalho. Não houve impacto, todavia, sobre a felicidade ou a realização pessoal dos trabalhadores (que também foram mensurados pelos instrumentos do estudo), ou seja, entendese que ações organizacionais reduzem as emoções negativas e as experiências estressantes próprias ao ambiente de trabalho, mas não necessariamente colaboram com a sensação de prazer no trabalho ou com a realização pessoal do profissional.
Tais atividades teriam, assim, base assistencialista e caráter meramente paliativo. Assim, mais que promover ações de promoção de saúde, devem as empresas zelar pela melhora das condições do ambiente de trabalho, atentando-se os gestores para componentes psicossociais da Organização.

Investimento em educação, autonomia e ações que aumentam a participação dos colaboradores nas decisões organizacionais são citados como fatores que podem aumentar o prazer no trabalho, o senso de realização pessoal e, por conseguinte, a felicidade (COUTO; PASCHOAL, 2017). Apesar disso, é importante reforçar que se mostra fundamental que as empresas, ao aplicar programas de qualidade de vida ou modelos de gestão humanizados atentem-se as suas especificidades, façam diagnóstico de suas demandas, e não meramente repliquem programas padronizados de modo imediatista. Ainda mais, tais ações não podem representar meros modismos, mas devem estar atreladas ao Planejamento Estratégico das Organizações, não podendo ser abolidas quando por ocasião de desafios ou dificuldades (ALVES, 2011).

Outros fatores que foram relacionadas ao bem-estar no trabalho, por Rocha Sobrinho e Porto (2012), foram variáveis demográficas (gênero, estado civil, idade e escolaridade), do clima social e estratégias de coping (enfrentamento do estresse). 2438 colaboradores de Instituição de Ensino confessional participaram da pesquisa. Não foi demonstrado grande impacto de fatores demográficos sobre o bem-estar no trabalho e, quando encontrado pequeno efeito, pôde-se associá-lo mais a fatores individuais (de personalidade). Por sua vez, o clima organizacional, sobretudo, nas dimensões de autonomia e de relacionamento interpessoal positivo se mostrou importante preditor de bem-estar organizacional (o mais forte preditor entre as variáveis deste estudo). As estratégias de coping empreendidas pelos colaboradores, especialmente de manejo e controle (excluem-se apenas as estratégias de esquiva), também foram apontadas como detentoras de correlação forte e positiva com o bem-estar dos colaboradores.

Pedroso (2010) aplicou questionários com 206 indivíduos, na região metropolitana de Curitiba - $\mathrm{PR}$, acerca de aspectos da felicidade no trabalho. $83 \%$ dos respondentes afirmaram se sentirem felizes no trabalho a maior parte do tempo. Quanto às razões associadas ao sentimento de felicidade, em ordem de importância para os respondentes, se tem: o trabalho que realizam (fazer o que se gosta), aspectos do ambiente, o reconhecimento e a valorização percebidos pelo trabalho realizado, as perspectivas de futuro relacionadas ao trabalho (crescimento e desenvolvimento pessoal e profissional) e, por fim, as outras pessoas (boa relação com colegas). Quanto aos motivos apontados para a infelicidade se tem, respectivamente (em ordem de importância): falta de reconhecimento no trabalho, falta de perspectivas de futuro, ambiente negativo, pessoas indesejáveis e baixos salários. Acrescenta-se a isto fatores como a falta de ética e de profissionalismo e o 
desequilíbrio entre a vida pessoal e profissional.

Silva e Tolfo (2012), em seu artigo teórico, ampliam o olhar sobre os determinantes pessoais da felicidade no trabalho e enfatizam que a satisfação ocupacional está muito atrelada à percepção de que o que se faz é significativo. Em resumo, as pessoas buscam encontrar um sentido na essência de suas ocupações, algo que faça "valer a pena" cada esforço realizado em prol da Organização ou de suas tarefas.

$\mathrm{Na}$ esteira desta compreensão mais individualizada do tema, Cruz, Ferreira e Gabardo-Mantins (2020) adaptaram para o contexto brasileiro e estão encontrando evidências de validade da Escala de Alegria no Trabalho, instrumento psicométrico que avalia o quão alegres são as pessoas em seus ambientes laborais e que poderá servir de subsídio para diagnósticos organizacionais e em futuras pesquisas científicas. A alegria no trabalho é vislumbrada, sob o referencial teórico adotado, como expressão do bem-estar no contexto laboral. Mais ainda, entende-se que a alegria no trabalho se reflete na satisfação com o contexto profissional e com a vida em geral.

Silva e Tolfo (2012, p.352), analisando o panorama das Organizações na contemporaneidade, apresentam prognóstico um tanto pessimista quanto ao tema:

Ainda que existam na atualidade ações nas organizações voltadas para a felicidade, o bem-estar e a qualidade de vida no trabalho, também perduram organizações cujos valores e crenças contribuem para a construção de competição destrutiva, o estabelecimento unilateral de metas percebidas como inalcançáveis e a construção de relacionamentos utilitários e egoístas, que não levam em conta princípios saudáveis de convívio entre seres humanos. [...] parece que nas sociedades atuais, em qualquer parte do mundo, as oportunidades de um trabalho significativo e motivador tendem a se tornarem cada vez menos possíveis.

Tal destaque dos pesquisadores deve servir para reforçar ainda mais a importância de que cientistas e gestores se debrucem sobre a temática e busquem proposições criativas e inovadoras para transformar o ambiente organizacional e, como consequência, ainda que pareça utópico, o Mundo do Trabalho como um todo. Maia e Maia (2019) reforçam que a área de Gestão de Pessoas tem negligenciado atuações visando promoção de bem-estar nas Organizações, talvez, inclusive, por desconhecer os seus efeitos. Partindo desta premissa pôde este estudo contribuir para a divulgação da área e de sua relevância.

Aponta-se, a priori, a artificialidade da ideia de que o trabalho é central na vida do homem. É legítimo dizer, todavia, que pode, sim, tornar-se o trabalho central à medida que, além de tempo e energia dispendidos, proporcione ao indivíduo saúde física e mental, autoestima, realização, desenvolvimento, ou seja, qualidade de vida, bem-estar e verdadeira felicidade (FARSEN et al, 2018).

\section{Conclusão}

Os dados recuperados da literatura sugerem que, apesar de haver, no presente, abundância de estudos relacionados à saúde, qualidade de vida, bem-estar ou felicidade nos contextos organizacionais, não há consenso teórico acerca das definições destes constructos, o que pode indicar que o referido campo de pesquisa se encontra, de certo modo, fragmentado. Desse modo, apesar de pesquisadores e gestores estarem se apercebendo da relevância desta problemática para a continuidade do modelo econômico vigente e para produção coletiva de saúde, ainda é apoucada a instrumentalização teórico-metodológica capaz de orientar e fomentar práticas inovadoras nos modelos de Gestão de Pessoas.

É importante levar em conta, como já mencionado, a necessidade de dar primazia ao fator humano nas Organizações. Se há a percepção de que a construção de um ambiente de trabalho saudável tem por única ou principal finalidade o aumento da produtividade, as atitudes da gestão, ainda que aparentemente positivas, tendem a ter efeito contrário e desestimular o trabalhador, que interpretará toda ação organizacional como cinismo, e não como estímulo ou cuidado.

Assim, desde o momento do planejamento até a operacionalização de programas de prevenção ou cuidado em saúde organizacional, faz-se de extrema valia que os objetivos últimos das ações em Gestão sejam realmente promover bemestar e felicidade.

Podemos dizer - a partir de uma perspectiva sociotécnica, que a satisfação das necessidades básicas dos colaboradores tem, por consequência, a qualidade de vida no trabalho. Nesse sentido, os modelos de mudanças ambientais ergonômicas começam paulatinamente a serem ampliados até ações mais robustas e profícuas no sentido de individualmente promover satisfação no trabalho e, por conseguinte, criar ambientes mais saudáveis, simplesmente porque nesses existem homens e mulheres mais felizes.

\section{Referências}

ALVES, E.F. Programas e ações em qualidade de vida no trabalho. InterfacEHS, v.6, n.1, p.60-78, 2011.

COUTO, P.R.; PASCHOAL, T. Relação entre ações de qualidade de vida no trabalho e bem-estar laboral. Psicol. Argumento, v.30, n.70, 2017. doi: http://dx.doi.org/10.7213/psicol.argum.6145

CRUZ, R.P.S.; FERREIRA, M.C.; GABARDO-MARTINS, L.M.D. Evidências de validade para a escala de alegria no trabalho. Rev. Psicol. Org. Trabalho, v.20, n.1, p.941-946, 2020. doi: http://dx.doi.org/10.17652/rpot/2020.1.16937

DE CARVALHO, M.B.; GONÇALVES, C.A.; PARDINI, D.J. A felicidade em foco-mensurando conceito metafísico para estratégia governamental e recomendações organizacionais. Rev. Adm. Univ. Federal de Santa Maria, v.3, n.2, p.269-287, 2010.

FARSEN, T.C. et al. Qualidade de vida, bem-estar e felicidade no trabalho: sinônimos ou conceitos que se diferenciam? Interação Psicol., v.22, n.1, 2018. doi: http://dx.doi.org/10.5380/psi. v22i1.48288

MAIA, T.S.T.; MAIA, F.S. Bem-estar no trabalho. Rev. Gestão Sustentab., v.1, n.1, p.352-366, 2019. doi: https://doi. org/10.36661/2596-142X.2019v1i1.11239

PASCHOAL, T.; TORRES, C.V.; PORTO, J.B. Felicidade 
no trabalho: relações com suporte organizacional e suporte social. Rev. Adm. Contemp., v.14, n.6, p.1054-1072, 2010. doi: http://dx.doi.org/10.1590/S1415-65552010000700005

PEDROSO, H.T. Felicidade no trabalho. Conhecimento Interativo, v. 4, n. 2, p. 181-191, 2010..

REGO, A. Empregados felizes são mais produtivos?. Tékhne, n. 12, p.215-233, 2009.
ROCHA SOBRINHO, F.; PORTO, J.B. Bem-estar no trabalho: um estudo sobre suas relações com clima social, coping e variáveis demográficas. Rev. Adm. Contemp., v.16, n.2, p. 253-270, 2012. doi: http://dx.doi.org/10.1590/S1415-65552012000200006

SILVA, N.; TOLFO, S.R. Trabalho significativo e felicidade humana: explorando aproximações. Rev. Psicol. Org. Trabalho, v.12, n.3, p.341-354, 2012. 